\title{
Relationship of psychological and oral health statuses with self-perceived halitosis in a Jordanian population: a cross-sectional study
}

\author{
Firas Q. Alzoubi ${ }^{*}$, Jumana A. Karasneh ${ }^{2}$ and Nidal M. Daamseh ${ }^{3}$
}

\begin{abstract}
Background: Self-perceived halitosis could be a symptom of a psychosomatic or psychogenic disorder. The aim of this cross-sectional study was to clarify the relationship of self-perceived halitosis with psychological and oral health statuses.

Methods: One hundred participants with a history of halitosis were enrolled from a teaching hospital. They were divided into the self-perceived and suggested groups if they sensed and did not sense the malodor, respectively. Demographic and socioeconomic information, smoking status, and oral hygiene practices were noted. Complete nasal, oral, and periodontal examinations with organoleptic tests (OLTs) and N-benzoyl-DL-arginine-2-naphthylamide (BANA) tests were conducted. The participants also completed the validated Arabic version of the 90 -item revised symptom checklist (SCL-90R). Data were compared by analysis of variance, chi-square test, Student's $t$-test, and multivariate logistic regression.

Results: The self-perceived group had higher OLT scores $(p=0.005)$ and were significantly younger $(p=0.001)$ than the suggested group. A significantly higher number of its participants were smokers $(p=0.004)$. No significant differences were observed in socioeconomic information, oral hygiene practices, oral conditions, and BANA test results. Further, no significant association was noted between self-perceived halitosis and the nine psychological dimensions of SCL-90R.

Conclusions: Halitosis is a multifactorial symptom that requires multidisciplinary management. Self-reporting of the condition is unique entity and trust worthy symptom. It tends to be related to nonoral pathologies and extrinsic causes such as smoking.
\end{abstract}

Keywords: Halitosis, Self-perception, Organoleptic test, BANA test, Psychopathology

\section{Background}

Halitosis is a frustrating symptom and a reason for frequent primary or secondary care visits. It is associated with a spectrum of disorders across multiple medical specialties, so it poses significant therapeutic challenges for dentists and physicians. Halitosis can originate from oral or nonoral sources [1]. In $90 \%$ of the cases, the causative factor is located in the mouth, such as deep carious lesions, periodontal disease, oral infection, pericoronitis, mucosal ulceration, food impaction, reduced salivary flow, and coated tongue

\footnotetext{
* Correspondence: firasz@just.edu.jo

'Division of Otolaryngology, Department of Special Surgery, Faculty of Medicine, Jordan University of Science and Technology, P.O. Box 3030, Irbid, Jordan

Full list of author information is available at the end of the article
}

[2]. Nonoral causes include paranasal and laryngeal lesions and systemic diseases such as diabetes mellitus [3].

Many oral bacteria produce volatile sulfur compounds (VSCs) [4]. Their presence in dental plaque or tongue coating is colorimetrically demonstrated by their ability to hydrolyze the synthetic trypsin substrate N-benzoyl-DL-arginine-2-naphthylamide (BANA) [5], producing blue pinpoints or patches, in the BANA test, a modern chair-side method. Further, the organoleptic test (OLT) is the gold standard to detect oral malodor [6], despite the introduction of techniques such as sulfide monitoring and gas chromatography. Instrumental sensors are useful for identifying VSCs alone, whereas the OLT can detect and recognize the compounds in complex mixtures. In addition, it is the only 
method of assessing the degree of social offensiveness of breath odor [7].

Sometimes, patients sense halitosis but the malodor is neither offensive nor noticeable [8]. Self-perception of halitosis may be related to a psychogenic or psychosomatic disorder [9]. It may indicate depression or obsessive-compulsive behavior, necessitating psychiatric care [10]. Anxiety itself increases the oral levels of VSCs [11], so many professionals do not consider self-reporting of halitosis reliable.

The aim of this cross-sectional study was to clarify the relationship of self-perceived halitosis with psychological and oral health statuses.

\section{Methods}

\section{Ethical statement}

The study was independently reviewed and approved by the Institutional Research Board (IRB) of Jordan University of Science and Technology (JUST). The purpose and methodology of the study, including possible future publication of clinical datasets, were fully explained to all participants and their written consent was obtained before interviews and examinations, complying with the tenets of the revised Declaration of Helsinki.

\section{Subjects}

A single clinician recruited 125 outpatients with a history of halitosis from King Abdullah University Hospital between January and April 2013. These individuals had visited the hospital for nonmedical reasons or problems not acutely related to otolaryngological and oral diseases. They were enrolled if they sensed halitosis (self-perceived group) or were advised about the malodor by a dentist, family member, or friend (suggested group). Those with acute infection, nasal obstruction, history of malignancy, diabetes mellitus, immunosuppression, any systemic condition affecting dental or periodontal disease, pregnancy, and edentulism were excluded.

\section{Data collection}

Demographic and socioeconomic information and smoking status were recorded. Oral hygiene practices were assessed through questions on the frequency of tooth brushing, flossing, miswak (chewing stick) use, and mouth rinse use.

A nasal examination was conducted to exclude nasal masses, septal perforation, and excessive crustation. An oral examination was also performed to detect ulcers, sinus tracks, signs of reduced salivary flow, and tongue coating. Four clinical variables were recorded: the decayed, missing, or filled teeth (DMFT) index, plaque index (PI), gingival index (GI) [12], and clinical attachment loss (CAL), which was measured at six sites around each tooth and averaged (Table 1). The periodontal
Table 1 Diagnostic test scores and definitions in this study

\begin{tabular}{|c|c|}
\hline \multirow[t]{4}{*}{ Tongue coating } & 0: Not apparent \\
\hline & $1:<1 / 3$ of the dorsum coated \\
\hline & $2: 1 / 3$ to $2 / 3$ of the dorsum coated \\
\hline & $3:>2 / 3$ of the dorsum coated \\
\hline \multirow[t]{4}{*}{ OLT } & 0: No odor present \\
\hline & 1: Slight malodor (barely noticeable) \\
\hline & 2: Moderate malodor \\
\hline & 3: Offensive malodor (strongly noticeable) \\
\hline \multirow[t]{3}{*}{ BANA test } & 0 : negative (no blue color) \\
\hline & $\begin{array}{l}\text { 1: weakly positive (faint blue color; corresponding } \\
\text { to } 10^{4}-10^{5} \text { colony-forming units) }\end{array}$ \\
\hline & $\begin{array}{l}\text { 2: strongly positive (definite blue color; } \\
\text { corresponding to } \geq 10^{6} \text { colony-forming units) }\end{array}$ \\
\hline Chronic periodontitis & $\begin{array}{l}\text { Presence of four or more teeth with at least } \\
\text { one site having PPD } \geq 4 \mathrm{~mm} \text { or } C A L \geq 3 \mathrm{~mm} \text {. }\end{array}$ \\
\hline Severity of periodontitis & $\begin{array}{l}\text { Percentage of sites affected by periodontal } \\
\text { disease (the number of involved sites divided } \\
\text { by the total number of sites measured) }\end{array}$ \\
\hline
\end{tabular}

OLT organoleptic test, BANA N-benzoyl-DL-arginine-2-naphthylamide, PPD periodontal pocket depth, $C A L$ clinical attachment loss

examination was repeated in 10 participants within 7 days to test intraexaminer reliability: the result showed $97 \%$ agreement between the examinations.

The participants were instructed to avoid drinking, eating, smoking, chewing gum, and mouth rinsing $2 \mathrm{~h}$ before the OLT and BANA test. In the OLT, each participant closed the mouth, did not swallow for $60 \mathrm{~s}$, and then exhaled gently through a 10-cm-long tube. The severity of malodor was immediately recorded on a fourpoint scale (Table 1). The BANA test [Hexagon International (GB) Ltd., Berkhamsted, UK] was performed and interpreted according to the manufacturer's instructions. Another examiner, who was blinded to the original readings, checked the presence and intensity of colors on the test strips to determine reliability. Agreement between the readings was $98 \%$.

The 90-item revised symptom checklist (SCL-90R) was used to assess psychological status. It includes three global indices with nine psychological dimensions relevant to general psychiatric distress [13]. The participants were asked to complete the validated Arabic version of the test while waiting [14]. They rated the extent to which each item was manifested during the preceding week using a five-point scale.

\section{Statistical analysis}

SPSS version 17 software (SPSS, Inc., Chicago, IL) was used for data processing and analysis. Categorical variables are presented as number of patients (\%) and continuous variables are shown as means and standard deviation. Analysis of variance and the chi-square test 
were used to determine intergroup differences. SCL-90R data were analyzed by two-tailed Student's $t$-test at the $5 \%$ significance level. Multivariate logistic regression was used to identify sociodemographic risk factors of psychological symptoms; adjusted odds ratios and $95 \%$ confidence intervals were calculated.

\section{Results}

Of the 125 recruited outpatients, 12 individuals were excluded because of upper respiratory tract, oral, or systemic diseases. Further, 13 participants did not adhere to the study protocol, complete the questionnaire, or have the full examination. Therefore, data of 100 participants (41 men and 59 women) were analyzed.

The mean age of the self-perceived group was significantly lower than that of the suggested group (47 years vs. 55.6 years; $p=0.001$ ). Most of the participants were unemployed and fewer than half had a university degree. Further, 67 participants brushed their teeth daily, but the other oral hygiene methods were not commonly used. The self-perceived group had a significantly higher number of smokers $(p=0.004$; Table 2$)$.

Table $\mathbf{2}$ Intergroup comparison of demographic and socioeconomic data, smoking status, and oral hygiene practices

\begin{tabular}{|c|c|c|c|}
\hline Characteristic & $\begin{array}{l}\text { Self-perceived } \\
\text { group }(n=50)\end{array}$ & $\begin{array}{l}\text { Suggested group } \\
(n=50)\end{array}$ & $P$-value \\
\hline Mean age (SD), years & $47.0(12.9)$ & $55.6(13.4)$ & $0.001^{*}$ \\
\hline Male gender (\%) & $24(48)$ & $17(34)$ & 0.155 \\
\hline Occupational status (\%) & & & 0.204 \\
\hline Employer/professional & $10(20)$ & $5(10)$ & \\
\hline Worker & $9(18)$ & $6(12)$ & \\
\hline Unemployed & $31(62)$ & $39(78)$ & \\
\hline $\begin{array}{l}\text { Low monthly income } \\
\left(<500 \mathrm{JOD}^{\mathrm{a}}\right)\end{array}$ & $38(76)$ & $41(82)$ & 0.461 \\
\hline Educational level (\%) & & & 0.588 \\
\hline Primary & $17(34)$ & $22(44)$ & \\
\hline High school & $11(22)$ & $9(18)$ & \\
\hline University & $22(44)$ & $19(38)$ & \\
\hline \multicolumn{4}{|l|}{ Smoking status } \\
\hline Smoker (\%) & $21(42)$ & $8(16)$ & $0.004^{*}$ \\
\hline Quantity (>20 cigarettes/day) & $12(57)$ & $4(50)$ & 0.470 \\
\hline Duration (>10 years) & $16(76)$ & $6(75)$ & 0.461 \\
\hline \multicolumn{4}{|l|}{ Oral hygiene practice (\%) } \\
\hline Brushing (at least once daily) & $35(70)$ & $32(64)$ & 0.143 \\
\hline Flossing & $2(4)$ & $7(14)$ & 0.081 \\
\hline Miswak use & $8(16)$ & $8(16)$ & 1.000 \\
\hline Mouth rinse use & $15(30)$ & $16(32)$ & 0.829 \\
\hline
\end{tabular}

${ }^{a} 1$ Jordanian Dinar (JOD) equals 1.4 US Dollars

$S D$ standard deviation

*statistically significant
The OLT scores showed that most of the participants in the self-perceived group had halitosis $(p=0.005$; Table 3$)$. When the scores of 0 and 1 were considered negative for halitosis, the sensitivity, specificity, and positive predictive value were $54 \%, 67 \%$, and $88 \%$, respectively. No significant differences in the presence of coated tongue, fissured tongue, and dental prosthesis or BANA test results were observed between the groups.

Regarding the SCL-90R, no significant association was noted between truly self-perceived halitosis (sensed by the participant and detected by the OLT) or delusional halitosis (sensed by the participant but not detected by the OLT) and the nine psychological dimensions (Table 4). Many participants in the self-perceived group had depression or anxiety ( $\mathrm{aOR}=1.04$ and 1.51 , respectively), although these results were not significant ( $p=0.092$ and 0.062 respectively).

\section{Discussion}

Bad breath is a stigma that can affect an individual socially and emotionally. It is an international problem affecting different cultures and societies [15-17]. The global prevalence of halitosis ranges from $15 \%$ to $50 \%$ $[18,19]$. In Jordan, its prevalence was recently reported to be $78 \%$, but the prevalence drops to $36 \%$ if barely noticeable oral malodor (OLT score $=1$ ) is considered negative for halitosis [20].

In this study, we tried to explore the self-perception of halitosis. Because cognitive, emotional, and psychological factors strongly influence its reliability, we included the

Table 3 Intergroup comparison of diagnostic test results and oral conditions

\begin{tabular}{|c|c|c|c|}
\hline Test/condition & $\begin{array}{l}\text { Self-perceived group } \\
(n=50)\end{array}$ & $\begin{array}{l}\text { Suggested group } \\
(n=50)\end{array}$ & $P$-value \\
\hline OLT score & & & $0.005^{*}$ \\
\hline 0 or 1 & 6 & 12 & \\
\hline 2 & 15 & 26 & \\
\hline 3 & 29 & 12 & \\
\hline BANA test score & & & 0.644 \\
\hline 0 & 10 & 10 & \\
\hline 1 & 24 & 28 & \\
\hline 2 & 16 & 12 & \\
\hline Tongue-coating score & & & 0.226 \\
\hline 0 & 7 & 10 & \\
\hline 1 & 19 & 17 & \\
\hline 2 & 15 & 20 & \\
\hline 3 & 9 & 3 & \\
\hline Fissured tongue & 17 & 16 & 0.832 \\
\hline Dental prosthesis & 22 & 27 & 0.403 \\
\hline Periodontitis & 22 & 32 & 0.067 \\
\hline
\end{tabular}

OLT organoleptic test, BANA N-benzoyl-DL-arginine-2-naphthylamide *statistically significant 
Table 4 Multivariate logistic regression results of the relationship between SCL-90R psychological dimensions and self-perceived halitosis

\begin{tabular}{|c|c|c|c|c|c|c|}
\hline Dimension & $\begin{array}{l}\text { Total self-perceived } \\
\text { population (aOR) }\end{array}$ & $P$-value & $\begin{array}{l}\text { OLT positive } \\
(\mathrm{aOR})\end{array}$ & $P$-value & $\begin{array}{l}\text { OLT negative } \\
(\mathrm{aOR})\end{array}$ & $P$-value \\
\hline Somatization & 1.06 & 0.715 & 1.09 & 0.350 & 1.04 & 0.978 \\
\hline Obsessive-compulsive & 1.18 & 0.529 & 1.20 & 0.340 & 1.15 & 0.987 \\
\hline Interpersonal-sensitivity & 0.88 & 0.560 & 0.91 & 0.090 & 0.86 & 0.716 \\
\hline Depression & 1.02 & 0.140 & 1.04 & 0.092 & 1.01 & 0.611 \\
\hline Anxiety & 1.48 & 0.120 & 1.51 & 0.062 & 1.45 & 0.566 \\
\hline Hostility & 0.89 & 0.562 & 0.95 & 0.604 & 0.83 & 0.218 \\
\hline Phobic anxiety & 0.67 & 0.792 & 0.64 & 0.386 & 0.652 & 0.550 \\
\hline Paranoid ideation & 0.83 & 0.248 & 0.85 & 0.386 & 0.816 & 0.950 \\
\hline Psychotism & 1.10 & 0.268 & 1.12 & 0.075 & 1.09 & 0.532 \\
\hline
\end{tabular}

SCL-90R 90-item revised symptom checklist, OLT organoleptic test, aOR adjusted odds ratio

psychopathological assessment to overcome this limitation. The participants with self-perceived halitosis were almost 9 years younger the other participants. This difference can be explained by the fact that young and middle-aged people tend to be more vigilant and anxious about their health [21].

Hydrogen sulfide, methyl mercaptan, and to a lesser extent, dimethyl sulfide account for $90 \%$ of the VSCs in breath, suggesting that they are responsible for halitosis [22]. Patients with periodontal disease frequently suffer from oral malodor, and a positive correlation has been demonstrated between severity of periodontitis and VSC levels [23]. The OLT suggests halitosis by the intensity of the malodor [10]. On the other hand, the BANA test indirectly indicates oral malodor by detecting red-complex bacteria. The test is negative when halitosis is not caused by these microorganisms or oral conditions, contributing to nearly $85 \%$ of all cases [24]. In this study, the participants with self-perceived halitosis had significantly higher OLT scores but showed no significant differences in oral conditions or BANA test results. These findings suggest that halitosis in people who sense oral malodor might be caused by nonoral factors, such as smoking [25]; smokers constituted $29 \%$ of the study population. The theory also explains the lack of significant differences in oral hygiene practices between the groups.

The participants who sensed halitosis and had a positive OLT finding tended to have depression or anxiety. Emotional status could have a negative impact on body image and the patient may become more sensitive to malodor, causing a multifactorial psychophysiological problem related closely to the psychopathological profile [26]. Two previous studies explored the psychological aspect of halitosis: they showed that a lower severity of halitosis is associated with a stronger psychopathological profile $[27,28]$. These studies included patients who attended halitosis clinics, already had the stigma with its psychological burden, and were obviously different from the present sample, who did not seek help. This may explain the lack of significant differences in relation to the SCL-90R findings in our study.

\section{Limitations of the study}

This study has some limitations. First, it was a crosssectional study of individuals recruited from the outpatient departments of a hospital, so the possibility of selection bias cannot be eliminated. However, we applied strict exclusion criteria and avoided recruiting patients from otolaryngology and oral medicine clinics; the strict criteria can weaken external validity and may not eliminate the bias. Second, the study was designed to include more than 100 participants; the sample size may be insufficient to give a stronger statistical difference. Consequently, larger and more representative communitybased studies are required.

\section{Conclusion}

Halitosis is a multifactorial symptom that requires multidisciplinary approach. Self-reporting of the condition is unique entity and reliable symptom. Younger individuals tend to sense oral malodor and seek help. Self-perceived halitosis is mainly related to nonoral pathologies and extrinsic causes such as smoking.

\section{Competing interests}

The authors declare that they have no competing interests.

\section{Authors' contributions}

ND carried out the periodontal examinations and collected the epidemiological data. JK performed the OLTS and BANA tests and drafted the manuscript. FA conceived of and designed the study, performed the otolaryngological examinations and statistical analyses, and helped to draft the manuscript. All authors read and approved the final manuscript.

\section{Acknowledgments}

The authors would like to thank all the staff of King Abdullah University Hospital for assisting in data collection. 


\section{Author details}

${ }^{1}$ Division of Otolaryngology, Department of Special Surgery, Faculty of Medicine, Jordan University of Science and Technology, P.O. Box 3030, Irbid, Jordan. ${ }^{2}$ Department of Oral Medicine and Oral Surgery, Dental School, Jordan University of Science and Technology, Irbid, Jordan. ${ }^{3}$ Private practice, Amman, Jordan.

Received: 12 February 2015 Accepted: 24 July 2015

Published online: 31 July 2015

\section{References}

1. van den Broek AM, Feenstra L, de Baat C. A review of the current literature on aetiology and measurement methods of halitosis. J Dent. 2007;35:627-35

2. van den Broek AM, Feenstra $L$, de Baat C. A review of the current literature on management of halitosis. Oral Dis. 2008;14:30-9.

3. Tangerman A, Winkel EG. Intra- and extra-oral halitosis: finding of a new form of extra-oral blood-borne halitosis caused by dimethyl sulphide. J Clin Periodontol. 2007:34:748-55.

4. Persson S, Edlund MB, Claesson R, Carlsson J. The formation of hydrogen sulfide and methyl mercaptan by oral bacteria. Oral Microbiol Immunol. 1990;5:195-201.

5. Tanner AC, Strzempko MN, Belsky CA, McKinley GA. API ZYM and API An-Ident reactions of fastidious gram-negative species. J Clin Microbiol. 1985;22:333-5.

6. Romano F, Pigella E, Guzzi N, Aimetti M. Patients' self-assessment of oral malodour and its relationship with organoleptic scores and oral conditions. Int J Dent Hyg. 2010;8:41-6.

7. Rosenberg M, Kulkarni GV, Bosy A, McCulloch CA. Reproducibility and sensitivity of oral malodor measurements with a portable sulphide monitor. J Dent Res. 1991;70:1436-40.

8. Yaegaki K, Coil JM. Genuine halitosis, pseudo-halitosis, and halitophobia: classification, diagnosis, and treatment. Compend Contin Educ Dent. 2000;21:880-9.

9. Scully C, El-Maaytah M, Porter S, Greenman J. Breath odor: etiopathogenesis, assessment and management. Eur J Oral Sci. 1997;105:287-93.

10. Bollen CM, Beikler T. Halitosis: the multidisciplinary approach. Int J Oral Sci. 2012:4:55-63.

11. Calil CM, Marcondes FK. Influence of anxiety on the production of oral volatile sulfur compounds. Life Sci. 2006;79:660-4.

12. Löe $\mathrm{H}$. The gingival index, the plaque index and the retention index systems. J Periodontol. 1967;38(Suppl):610-6.

13. Derogatis $L R$, Cleary PA. Factorial invariance across gender for the primary symptom dimensions of the SCL-90. Br J Soc Clin Psychol. 1977;16:347-56.

14. Abdallah T. Reliability and validity of Palestinian Student Alienation Scale. Adolescence. 1997;32:367-71.

15. Söder B, Johansson B, Söder PO. The relation between foetor ex ore, oral hygiene and periodontal disease. Swed Dent J. 2000;24:73-82.

16. Frexinos J, Denis P, Allemand H, Allouche S, Los F, Bonnelye G. Descriptive study of digestive functional symptoms in the French general population [article in French]. Gastroenterol Clin Biol. 1998;22:785-91.

17. Miyazaki H, Sakao S, Katoh Y, Takehara T. Correlation between volatile sulphur compounds and certain oral health measurements in the general population. J Periodontol. 1995;66:679-84.

18. Nadanovsky P, Carvalho LB, Ponce De Leon A. Oral malodour and its association with age and sex in a general population in Brazil. Oral Dis. 2007;13:105-9.

19. Meningaud JP, Bado F, Favre E, Bertrand JC, Guilbert F. Halitosis in 1999 [article in French]. Rev Stomatol Chir Maxillofac. 1999;100:240-4.

20. Hammad MM, Darwazeh AM, AI-Waeli H, Tarakji B, Alhadithy TT. Prevalence and awareness of halitosis in a sample of Jordanian population. J Int Soc Prev Community Dent. 2014;4 Suppl 3:S178-86.

21. McCrae RR, Bartone PT, Costa PT. Age, anxiety, and self-reported health. Int J Aging Hum Dev. 1976;7:49-58.

22. Solis-Gaffar MC, Niles HP, Rainieri WC, Kestenbaum RC. Instrumental evaluation of mouth odour in a human clinical study. J Dent Res. 1975;54:351-7.

23. Yaegaki K, Sanada K. Volatile sulfur compounds in mouth air from clinically healthy subjects and patients with periodontal disease. J Periodont Res. 1992;27:233-8.
24. Quirynen M, Dadamio J, van den Velde S, De Smit M, Dekeyser C, Van Tornout M, et al. Characteristics of 2000 patients who visited a halitosis clinic. J Clin Periodontol. 2009;36:970-5.

25. Al-Atrooshi BA, Al-Rawi AS. Oral halitosis and oral hygiene practices among dental students. J Bagh Coll Dent. 2007;19:72-6.

26. Eli I, Baht R, Koriat H, Rosenberg M. Self-perception of breath odor. J Am Dent Assoc. 2001;132:621-6.

27. Oho T, Yoshida Y, Shimazaki Y, Yamashita Y, Koga T. Psychological condition of patients complaining of halitosis. J Dent. 2001;29:31-3.

28. Suzuki N, Yoneda M, Naito T, Iwamoto T, Hirofuji T. Relationship between halitosis and psychologic status. Oral Surg Oral Med Oral Pathol Oral Radiol Endod. 2008;106:542-7.

\section{Submit your next manuscript to BioMed Central and take full advantage of:}

- Convenient online submission

- Thorough peer review

- No space constraints or color figure charges

- Immediate publication on acceptance

- Inclusion in PubMed, CAS, Scopus and Google Scholar

- Research which is freely available for redistribution 